\title{
Cyber-crimes Against Womenfolk on Social Networks: Bangladesh Context
}

\author{
Sabbir Ahmed \\ Department of Computer Science \\ American International University-Bangladesh \\ Dhaka, Bangladesh \\ Sazia Sharmin Ahmed Sneha \\ American International University-Bangladesh \\ Dhaka, Bangladesh
}

\author{
Anwarul Kabir \\ Department of Computer Science \\ American International University-Bangladesh \\ Dhaka, Bangladesh \\ Samia Jafrin \\ American International University-Bangladesh \\ Dhaka, Bangladesh
}

\begin{abstract}
In recent years, the participation in social networking sites has increased dramatically in Bangladesh. The social networking service like Facebook allows creating online profiles and the sharing of personal data with vast networks of friends - and, often, unknown numbers of strangers. Research has demonstrated that, the impact of threats affects more the female users rather than the male users. In Bangladesh mostly it is seen that, the victims do not want to take recourse to law for various reasons, especially for social fear and humiliation. Proper law utilizations of the existing cyber laws and new law should be proposed by the law agencies to minimize the threats, as well as people should be more aware and ethical morally.
\end{abstract}

\section{General Terms}

Security and Privacy, Cyber Crime

\section{Keywords}

Facebook, privacy, cyber law, social network, victim

\section{INTRODUCTION}

Social networking sites (SNSs) have opened the doors of communication by allowing people from around the world to engage in identity creations and relationship development [1]. Bangladesh has not lack behind from this culture. SNS like Facebook.com have become a significant part of adolescent Bangladeshi culture [2]. But these social technologies are serving as an obstacle to young people through disclosing large amounts of personal information and putting themselves at a variety of privacy risks especially for the women. While social media connect us to more digital relationships, at the same time, they deteriorate our ability to maintain healthy relationships in real life [1].

In this paper, the study take the first step towards focusing the factors threatening womens right to privacy for using these social networks like Facebook. This study will mainly focus on the women users and analyze their potential risks with the disclosure of personal information on SNSs like Facebook. This paper also suggests the measures which may taken by the women users to facilitate their rights to online privacy. In particular, this research center the analysis on two questions:

(1) What are the threats hampering womens privacy in Bangladesh using Facebook? What is the current scenario of Bangladesh for Women users?

(2) Is there potential aid for women to overcome these threats? How can we reduce the mental burden on women users for using Facebook without any questions about privacy harassment?

This study mainly focuses on the potential attacks on various aspects of women's right to privacy and consequences faced by women by revealing the personal information to Facebook in Bangladesh. The study will also investigate to explore the factors relating privacy awareness on Bangladeshi women to minimize the potential risk to privacy.

\section{LITERATURE REVIEW}

Several studies have attempted to determine the reasons why social network users are unconcerned and unaware of the privacy concerns associated with their online practices, but the reasons prove to be numerous and varied. Gross et.al in their research considers the privacy implications that arise from social networking sites upon their transition from "niche phenomenon to mass adoption" [3]. They said, the real privacy concerns arise when users allow to unknown people and would not trust to have access to the personally identifiable information they have made available. The authors also explained that the people do this disclosure of information because they are unaware of the large number of people who are allowed to view this information and the implications associated with these viewings. Gross and Acquisti explain that such practices allow "third parties to create digital dossiers of their behavior" [3]. Similar research has been done by Young and Hasse. They studied the strategies students have developed to protect themselves against privacy threats. The results showed that personal network size was positively associated with information revelation, no association was found between concern about unwanted audiences and information revelation and finally, students internet privacy con- 
cerns and information revelation were negatively associated. Based on their findings, they proposed a model of information revelation and draw conclusions for theories of identity expression.

According to the authors Jones and Soltren, "Facebook is undermined by three principal factors: users disclose too much, Facebook does not take adequate steps to protect user privacy, and third parties are actively seeking out end-user information using Facebook" [4]. So their research encouraged using the real names to (re)present an account profile to the rest of the online community. The authors also said "The environment that Facebook creates should be one that fosters good decision-making" so that "privacy should be the default, encryption should be the norm, and Facebook should take strides to inform users of their rights and responsibilities [4]. In [2], researchers investigated of the privacy settings offered by each website, we found that users are generally unaware and/or unconcerned with protecting their privacy on social networking sites. They have rated Facebook.com 4 because the website limits global far-reaching searches and its platform is user friendly. They concluded the responsibility of providing privacy does not lie to the sites rather privacy should rest solely on the individual users.

In [1], Pugh studied computer-mediated environments (personal Websites) to develop theory of how people contemporarily define themselves in their social online space. Author brought the Facebook user celebrity experience through connected networks/fan base, a highly regarded image, and developed associations throughout the analysis [5]. Mazman and Usluel have analyzed the usage purposes of social networks focusing on the possible differences between females and males. These usage purposes can be categorized under four categories, namely maintaining existing relationships, making new relationships, using for academic purposes and following specific agenda. The difference on making new contacts was in favor of males, the differences on the other three user purposes were in favor of females [6].

In [7], authors investigated to explore the factors relating privacy awareness on Bangladeshi undergraduate students to focus actual influencing factors and aggregated relationship with Awareness of Facebook Privacy. They concluded that, Bangladeshi students do care about their privacy on Facebook, and a large number of them are now making regular changes to their settings. A seminar has been held by "Contemporary Thinking on Managing Business" in Bangladesh. On this seminar, researchers showed that almost 75 percent male tried to find new friends in Facebook; however, found close relationship between Facebook users gender and find new friends. This paper reveals comprehensive analysis between Bangladeshi users age and gender, and other common activities perform in Facebook [5].

\section{DATA GATHERING AND ANALYSIS}

\subsection{Social Networking Sites and Facebook}

A social networking service is a platform to build social networks or social relations among people who, for example, share interests, activities, backgrounds, or real-life connections. It consists of a representation of each user (often a profile), his/her social links, and a variety of additional services. Most social network services are web-based and provide means for users to interact over the Internet, such as e-mail and instant messaging [8]. Social networking sites allow the users to share ideas, pictures, posts, activities, events, and interests with people in their network.

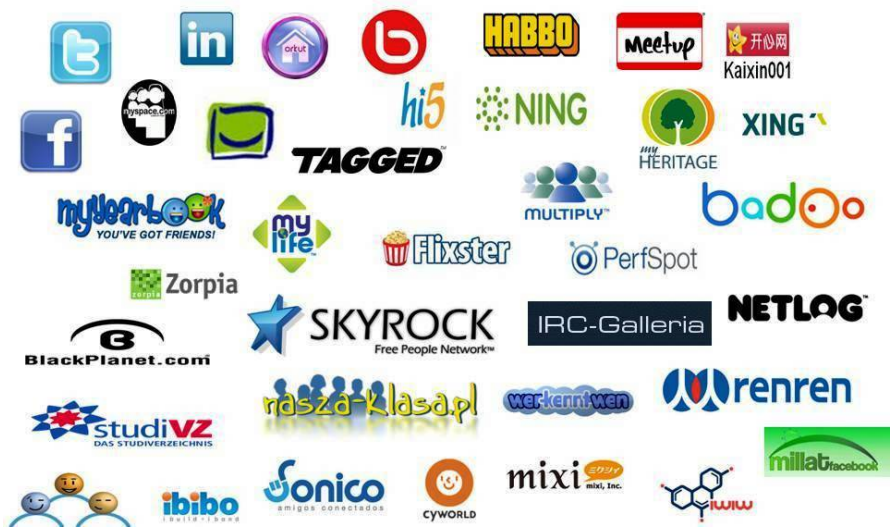

Fig. 1. The different types of popular social networks and blogs.

Different countries have their own social networking sites. Among them the popular sites includes Facebook, Google+, tumblr, Twitter (USA based sites), Nexopia in Canada, Badoo, Bebo, VKontakte, Delphi, Hi5 \& Hyves (mostly in The Netherlands), Cyworld, Mixi, Orkut, renren, weibo and Wretch in Asia and the Pacific Islands [9]. In Bangladesh Facebook, Hi5, Twitter, Google+ etc are mostly used.

Facebook is one of the popular SNS which has over millions of members connecting with friends every day with new members joining daily. It is also free of cash which adds a reason why it is so popular. In this busyness era, Facebook has made the way easy to be connected with one another.

Markoff commented that Facebook has been created by two striving Harvard students, Mark Zuckerberg, along with his college roommates and fellow student. It was launched on 4th February in 2004 [10]. In [11], Phillips wrote that the site was originated as "theFacebook.com" and encouragement from the books of student who provides headshot photos and basic biographical data distributed to Harvard students at the beginning of the academic year by university administrations to assist students and get to know each other. Arrington [12] added that Facebook is rolling as a college-based service and visible to the key of assignment of Networks. Usually, a "Facebook Network" is a collection of users with a school, workplace, or region in common. To have access to a college or company network, he or she must have an email associated with the relevant organization.

Social networking has been a common use on the internet in todays generation. Throughout the past, we had social networking sites which did not make it uphold a longer life than those which have ended up being very popular. While social media connect us to more digital relationships, at the same time, they deteriorate our ability to maintain healthy relationships in real life [7]. So despite having so many the good uses of Facebook, it has also several disadvantages. If youre not a user of Facebook yet, you will soon realize yourself the problems that Facebook can cause.

\subsection{Facebooks Privacy Policy}

Facebook wants to assure users that it deals responsibly with their data and that users are in full control of privacy controls. Therefore as an introduction to the privacy issue, it writes: "Facebook is about sharing. Our privacy controls give you the power to decide what and 
how much you share" (Facebook privacy policy). The complexity and length of the policy makes it unlikely that users read it in detail. Facebook on the one hand says that it uses the users data to provide a "safe experience", but on the other hand uses targeted advertising, in which it sells user data to advertisers: "We allow advertisers to choose the characteristics of users who will see their advertisements and we may use any of the non-personally identifiable attributes we have collected (including information you may have decided not to show to other users, such as your birth year or other sensitive personal information or preferences) to select the appropriate audience for those advertisements [12].

The privacy policy also allows Facebook to collect data about users behaviour on other websites and to commodity this data for advertising purposes: "Information from other websites. We may institute programs with advertising partners and other websites in which they share information with us". These data can be stored and used by Facebook, according to its privacy policy, for 180 days.

Facebook receive a number of different types of information about users, including [12]:

-When we sign up for Facebook, we are required to provide information such as our name, email address, birthday, and gender. In some cases, we may be able to register using other information, like our telephone number.

- The information we choose to share on Facebook, such as when we post a status update, upload a photo, or comment on a friend's story.

- The information about us from our friends and others, such as when they upload our contact information, posts a photo of our, tag us in a photo or status update, or at a location, or add us to a group.

-Data about us whenever we interact with Facebook, such as when we look at another person's timeline, send or receive a message, search for a friend or a Page, click on, view or otherwise interact with things, use a Facebook mobile app, or purchase Facebook Credits or make other purchases through Facebook.

-When we post things like photos or videos on Facebook, it may receive additional related data (or metadata), such as the time, date, and place we took the photo or video.

-Data from the computer, mobile phone or other device we use to access Facebook, including when multiple users log in from the same device. This may include our IP address and other information about things like our internet service, location, the type (including identifiers) of browser we use, or the pages we visit. For example, Facebook may get our GPS or other location information so it can tell us if any of our friends are nearby.

-Data whenever we visit a game, application, or website that uses Facebook Platform or visit a site with a Facebook feature (such as a social plugin), sometimes through cookies.

This may include the date and time we visit the site; the web address, or URL, technical information about the IP address, browser and the operating system we use; and, if we are logged in to Facebook, our User ID.

\subsection{End Users Interaction with Facebook Privacy}

All data fields on Facebook may be left blank, aside from name, e-mail address, and user status. A minimal Facebook profile will only tell a user's name, date of joining, school/ college/ university, status, and e- mail address. Any information posted beyond these
Table 1. Different type of Facebook features with their category

\begin{tabular}{|l|l|}
\hline Category & Feature details \\
\hline My Profile & $\begin{array}{l}\text { Contains "Account Info", "Basic Info", "Contact } \\
\text { Info", "Personal Info", "My Groups", and a list of } \\
\text { friends \& family }\end{array}$ \\
\hline The Wall & $\begin{array}{l}\text { Allows other user to post notes in the space on one's } \\
\text { profile }\end{array}$ \\
\hline My Photos & $\begin{array}{l}\text { Allows users to upload photographs and level who is } \\
\text { in each one. If a friend lists me as being in a photo, } \\
\text { there is a link added from my profile to that photo. }\end{array}$ \\
\hline My Groups & $\begin{array}{l}\text { Users can form groups with other like-minded users } \\
\text { to show support for a cause, use the available message } \\
\text { boards, or find people with similar interests. }\end{array}$ \\
\hline
\end{tabular}

basic fields is posted by the will of the end user. Although the required amount of information for a Facebook account is minimal, the total amount of information a user can post is quite large. Userconfigurable setting on Facebook can be divided into eight basic categories: profile, friends, photos, groups, events, messages, account settings, and privacy settings. For the purposes of this paper, we will investigate profiles, friends, and privacy settings.

Profile information is divided into six basic categories: Basic, Contact Info, Personal, Professional, Courses, and Picture. All six of these categories allow a user to post personally identifiable information to the service. Users can enter information about their home towns, their current residences and other contact information, personal interests, job information, and a descriptive photograph. We will investigate the amount and kind of information a typical user at a given school is able to see, and look for trends. A major goal of Facebook is to allow users to interact with each other online. Users define each other as friends through the service, creating a visible connection.

"My Privacy" Facebook's privacy features give users a good deal of flexibility in who is allowed to see their information. By default, all other users at a user's school are allowed to see any information a user posts to the service. The privacy settings page allows a user to specify who can see them in searches, who can see their profile, who can see their contact info, and which fields other users can see. In addition, the privacy settings page allows users to block specific people from seeing their profile. As per the usage agreement, a user can request Facebook to not share information with third parties, though the method of specifying this is not located on the privacy settings page.

\subsection{Privacy Threats for Women on Facebook}

Women are more likely to log into Facebook, have more friends, and have a higher percentage of friends. Both genders are equally unfamiliar with Facebook's Terms of Service and Privacy Policy. A survey [4] observed that Women were more likely to use Facebook's "My Privacy" feature, but not to a statistically significant level. Women definitely self-censor their Facebook data more than men do. This is pronounced in the number of mobile phone numbers made available to the public.

3.4.1 Cyber Defamation. It is an act of imputing any person with intent to lower the person in the estimation of the right thinking members of society generally or to cause him/her to be shunned or avoided or to expose him/her to hatred, contempt or ridicule. Cyber defamation is not different from conventional defamation except the involvement of a virtual medium. E.g. the Facebook account of 
Table 2. "My Privacy" settings for Facebook users(default privacy set by the Facebook are in bold)

\begin{tabular}{|c|c|}
\hline Privacy options & User accessibility \\
\hline Visibility to Search & $\begin{array}{l}\text { Everyone } \\
\text { Friends of friends }\end{array}$ \\
\hline Profile Visibility & $\begin{array}{l}\text { Everyone } \\
\text { Friends of friends } \\
\text { Only friends } \\
\text { Customize }\end{array}$ \\
\hline Contact Info Visibility & $\begin{array}{l}\text { Everyone } \\
\text { Friends of friends } \\
\text { Only friends } \\
\text { Customize }\end{array}$ \\
\hline Can send message & $\begin{array}{l}\text { Everyone } \\
\text { Friends of friends } \\
\text { Only friends }\end{array}$ \\
\hline Profile also shows... & $\begin{array}{l}\text { My friends } \\
\text { My last login } \\
\text { My upcoming events } \\
\text { My courses } \\
\text { My wall } \\
\text { Groups that a lot of my friends are in }\end{array}$ \\
\hline
\end{tabular}

Ms. $\mathrm{R}$ was hacked and some irrelevant photos were sent from her account to some of her batch mates with intent to defame her.

3.4.2 Fraudulence \& Cheating. Online fraud and cheating via social media is one of the most lucrative businesses that are growing today. It may assume different forms. Some of the cases of online fraud and cheating that have come to light are those pertaining to credit card crimes, contractual crimes, offering jobs, etc. nowadays social media is become a great source for e-marketing. Most of the business owner is willing to do marketing via giving advertise on social media and few fraud people is taking this opportunities to cheat users. As women are fond of shopping thus they are being targeted most often by this kind of actions. E.g. suppose an advertise on Facebook is saying "if you buy one product from our site then you'll get five more products absolutely free." Now this is definitely an eye catchy offer and naive user will go on the site and buy product while giving their credit card information to get those free product. Thus their credit card information is stolen.

3.4.3 Hacking. "Hacking" is a specific concept of stolen data and information from any computer through network. It is actually an illegal intrusion into a computer system without the permission of the computer owner/user. Hackers usually do that with the intention of obtaining confidential information. Nowadays it is seen that some link with some eye catchy or shocking new/photos is provided by different users on other user Facebook wall. Interested users click on those link and actually become hacked by those link provider. E.g. on Ms. A's profile there was a link saying "click the link to see your favorite actors latest photo and news. In spite of knowing anything she just click the link to see photos and news, her Facebook account was hacked."

3.4.4 Women Trafficking. Human trafficking is an abhorrent phenomenon. Bangladesh is a source and transit country for men, women, and children trafficked for the purposes of forced labor and commercial sexual exploitation [13]. Author said "Trafficking in women consists of all acts involved in the procurement, transportation, forced movement, and/or selling and buying of women within and/or across border by fraudulent means, deception, coercion, direct and/or indirect threats, abuse of authority, for the purpose of placing a woman against her will without her consent in exploitative and abusive situations such as forced prostitution, forced marriage, bonded and forced labor, begging, organ trade, etc" [13]. This trafficking has been occurring internally and also across the border to India, Pakistan, Malaysia and many Middle Eastern countries [14].

Now-a-days, Facebook is used as a channel for human trafficking. This is a regular scenario for the recent times around the world. In an online news of Indonesia reported that the Chief of Crime and Investigation, Toni Surya Saputra, Indonesia said that based on the suspect's confession, all victims are put to the market through Facebook. In Bangladesh, this practice has already started.

There are some strategies which are adopted by the traffickers involved in the national and international human trade in Bangladesh through Facebook. Like love affairs, promise of marriage, fraudulence etc. Sometimes it is seen that as Facebook has become a great social interaction media, people get into several love affair relationships through it. People do not see each other, but get into relationship through trust. But some fraud traffickers use Facebook to get into such affairs with young girls or women. Traffickers pretend to be in love with young girls and asking them to elope. The girls believe them and leave their parents/home with their boyfriends full of illusions about a happy married life. Thus they get caught. In addition to the strategy of alluring girls with love affairs, promises of marriage and a better future, the traffickers also take full advantage of the cultural practice of arranged marriages by parents.

There is such a great procedure for trafficking using Facebook. The social network Facebook has applications like Photos to ease the trafficking procedures. The client looks through the photos and contacts the "agent" once he decides to buy one of the girls. Even though these groups are created only for private members, but the choice of using Facebook is still shocking which definitely a treat to women's privacy.

3.4.5 Pornography. Many of the photos that wind up on the site are "revenge porn" that is the pornographic souvenirs from relationships gone sour. Recent times, a trend of revenge taker has been observed. They post intimate photos of the victims on Facebook. Women are mostly the victims. Then Ex-partners post their intimate pictures or videos just for taking revenge form them or sometimes it's a business also. Sometimes women are given threats of uploading such pictures or videos just for harassing or abusing. Women face such privacy threats in a massive way in Bangladesh also. As a consequence to this, sometimes victims become mentally weak and harassed, become physically ill, madness occur or as a worst case commit suicidal act.

\subsection{A Survey on female Facebook users of Bangladesh}

The purpose of the survey was to determine how the female users are getting involved themselves with Facebook and also try to figure out whether they faced any kind of harassing or unusual condition for that involvement.

First 2 questions was formulated to evaluate the interest of using social networking website Facebook. We have found all of them $(100 \%)$ are using social networking websites specially Facebook. From question number 4 we have observed that around 90\% users are spending more than 1 hour time with Facebook in a particular day [15]. Question number 3 and 5 basically focused on the interactions between friends with whom they connected in their Facebook account. The survey results shows that $68.4 \%$ users try to find 


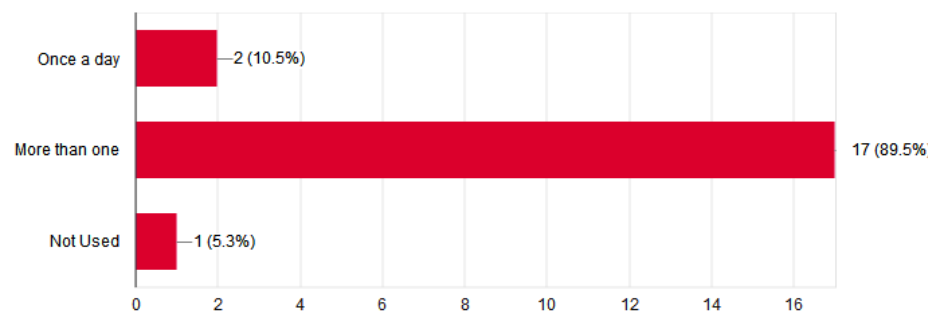

Fig. 2. The frequency of using facebook in a particular day.

Table 3. Responses due to harassment in Facebook

\begin{tabular}{|l|l|l|}
\hline Responses regarding harassment & yes & no \\
\hline Facing harassment & $36.8 \%$ & $63.2 \%$ \\
\hline Harassment from new people & $21.1 \%$ & $84.2 \%$ \\
\hline Unusual situations treat as harassment & $26.3 \%$ & $78.9 \%$ \\
\hline Harassment from different perspectives & $42.1 \%$ & $57.9 \%$ \\
\hline
\end{tabular}

their friends at Facebook and also 73.7\% users are doing frequent communications from their Facebook account. $63.2 \%$ users are like to build a connections with new peoples at Facebook founded from Question-6 [15].

Question 7-10 was articulated to find out whether the users ever faced unusual situation that can be treat as harassment ans also figure out from whom they had faced the harassment. First of we have found $36.8 \%$ users had been harassed, and $78.9 \%$ people are facing unusual situations which can be treat as harassment. From our data we have found $84.2 \%$ users had been harassed by the people with whom they are connected at Facebook. Most of the harassment around $27 \%$ are coming from the unknown people met at Facebook first time. We also found harassment $10.5 \%$ from completely unknown and 5.3\% from known person [15].

\subsection{Some Case in Bangladesh}

Some criminals take pictures or collect pictures from Facebook of female students and then write blogs to publish or distribute the obscene content in Facebook to embarrass them. According to the media, many victims keep quiet to avoid embarrassment and a few become mentally imbalanced.

Victim-1 (16 years old) had maintained a Facebook account and developed a relationship with a man who claimed to be working in a bank in Dhaka. After a few months of chatting, he demanded explicit pictures of herself and while she refused the man began to send her highly inappropriate images and videos with derogatory comments about her appearance and character. While victim-1 tried to block and delete him from his friend list, he threatened to call her parents. For this scared victim-1 take blame on herself and attempted suicide [16].

"When I was doing my $\mathrm{O}$ levels, there was this group of 4-5 boys who liked me at the same time. They had all asked me out separately but I wasn't interested. They decided to take revenge by taking my photo on MSN, photoshopping a naked body to my face and sending it to everyone in the class, and to my brother," says victim-2, a young professional. "The photo looked so real that my brother nearly threw up. I couldn't go to class for about two weeks after that because everyone called me a slut and made fun of the whole thing. One of them also threatened to send the photo to my parents if I didn't answer his calls all the time. They also opened a fake Facebook account with those photos." [16]

Victim-3, student of Class IX, talks about why she never shared her story of harassment with anyone: "I used to Skype with a close male friend who was living at UK. One day, I don't know if he was drunk, but he turned on his camera and he was naked, showing me his thing! I couldn't tell anyone about it. We had many common friends and I was afraid that people would exaggerate and say bad things about me. Maybe they would have said I had engaged in cyber sex." [16]

A vocal young women's rights activist says, "There is a Facebook page with an extremely offensive title. Someone (a fake profile) took photos of me, from different places friend's albums, my own profile pictures, photos from public events and posted them on the page. My friends and I have tried to get Facebook to take the page down, and remove the photos, but they have continuously responded that the page does not break any of their community rules, even though the page mainly has pornographic images on it. I decided to give up after sometime." [16]

The humiliation victim-1, victim-2 and victim- 3 faced is emerging as a big social problem in Bangladesh. The number of such incident is increasing day by day. This growing menace has added a new dimension to the already social violence against women like torture for dowry, acid attack, rape, abduction and trafficking.

"The harassment of women in our society has got a new dimension with the advancement of information technology," says Dr Jerina Begum, a professor of Dhaka University's Information Technology Institute. She says on one hand the internet has eased the life in many ways and made the lives of many women disastrous on the other [17].

The problem in Bangladesh is women still are not open to immediately report the cyber abuse or cyber crime. In reality it is seen many who chat with friends enjoy teasing their girlfriends by using words such as "sexy", "attractive" which are the virtual beginning of cyber obscenity. They slowly take their female friends into confidence and start discussing about their own problems like a true friend. Hence on many occasions they are successful in turning the net friendship into a strong bond and gradually proceed to send obscene or derogatory remarks. If the recipient shies away, the sender of such messages would become more encouraged to continue [16].

\subsection{What the Law of Bangladesh says}

According to the Section 57[ICT (Amendment) Act-2013] of the ordinance, if any person deliberately publishes any material in electronic form that causes to deteriorate law and order, prejudice the image of the State or person or causes to hurt religious belief the offender will be punished for maximum 14 years and minimum 7 years imprisonment. It also suggested that the crime is non-bailable [18].

In the original ICT Act-2006, the maximum punishment was 10 years jail term and a fine of Tk 1 crore. And police had to seek permission from the authorities concerned to file a case and arrest any person involved in crimes covered under the law [19].

According to 'The Information and Communication Technology Act 2006', it is a crime to release one's personal photo on the internet, no matter how, when and why it was taken. But photos of girls and women, mostly the ones taken in close proximity during any emotional time, are uploaded on the internet in an effort 
to blackmail the girls or women, creating an embarrassing situation not only for the girl, but also for the family. In most cases, the victims do not want to take recourse to law for various reasons, including social humiliation [16].

Bangladesh has formed a fast-track court (2013) to try cyber criminals after a spike in crimes involving mobile phones and social networking sites such as Facebook. Officials said the Cyber Tribunal, the first of its kind in the country, will be empowered to conclude trials within six months.

\section{DISCUSSION}

The overall study has been conducted with the help of analytical methods. The main data collection techniques used in this research study were document reviews, web sites, published articles, published papers, newspapers, and online journals.

"Around 73 percent women internet users in Bangladesh are facing cyber crimes", said by State Minister for Posts and Telecommunications. The state minister also said that around 84 percent of the women internet users facing cyber crimes were between the age group of 18 to 34 years. Currently there are 6.67 crore internet users in the country, according to BTRC. [20] There are 2732620 Facebook users in Bangladesh. Among them there are $21 \%$ female users. Mostly it is seen that teenagers (18-24yrs) are the key Facebook users [21]. From the review we observed that women get more friend requests from strangers other than man. As the numbers of users are mostly teenager, they are less concerned about the privacy settings of Facebook. So the default privacy settings remain as it is and most of the default privacy settings remain "Public" that is accessible by every registered Facebook user. Recently a trend is seen that Facebook owners change their site features more frequently, so by default the privacy option get changed.

In Bangladesh government has cyber laws but the enforcement of these laws is not implemented properly. In terms of well-developed countries there are sophisticated cyber laws which are enforced critically. Thus people get proper judgment if any kind of privacy violation happens. But in Bangladesh mostly it is seen that, the victims do not want to take recourse to law for various reasons, especially for social fear and humiliation. Women, who get victimized, remain quite without reporting to the police station or other law enforcement agencies. As there is no proper enforcement of these cyber laws the dishonest people get involved doing these crimes again and again without any fear. On the other hand, there are some few people who reports to the police station about these offenses but the criminals get themselves free by giving bribes to the law agencies or influencing them through several threats.

In this paper authors are suggesting some potential aid which the female user can follow to minimize the privacy threats in Facebook.

- Settings of privacy option: Customizing Facebook privacy settings depending upon priorities

-Regularly check your exposure: Checking of Facebook privacy settings periodically

— Think before you add: Be aware of accepting stranger friend request

- "UnPublic" your wall: User should set the wall posts to just friends and awareness should be set while giving "Personal Information" access based on priorities

-Block the snoopers or strangers: Block the unnecessary or irritating users
-Law utilizations: Proper enforcement of the existing cyber laws without any biasness. New law should be proposed by the law agencies

-Exposure without fear: Victims should report to the law agencies without the fear of humiliation

- Social awareness: People should be more aware and ethical morally. The victims should be supported rather humiliated.

\section{CONCLUSION AND FUTURE WORK}

Social networking interactions do not remove the people from their offline world but indeed used to support relationships and keep people in contact, even if they move away from each other. Facebook technology has immensely emerged in recent times. Though it was created for good cause but it brings privacy threats due to unethical people. In fact, problem is not using the technology. The problem is using it unconsciously. The impact of these threats affects more the female users rather than the male users. Criminal offenses like Cyber Defamation, Fraudulence \& Cheating, Pornography, Women Trafficking and Hacking. In Bangladesh mostly it is seen that, the victims do not want to take recourse to law for various reasons, especially for social fear and humiliation. Women, who get victimized, remain quite without reporting to the police station or other law enforcement agencies. As there is no proper enforcement of these cyber laws the dishonest people get involved doing these crimes again and again without any fear. Proper law utilizations of the existing cyber laws without any biasness and new law should be proposed by the law agencies to minimize the threats. People should be more aware and ethical morally. The victims should be supported rather humiliated, so that they can report to the law agencies without the fear.

The study only focuses on Facebook, hence the proposed approach could be used for other social networking sites. Also, this study approach needs to be applied to larger datasets to acquire better and more accurate result.

Acknowledgment: First of all we would like to be grateful to the almighty Allah who gives us the effort to work on this research. Thanks to our honourable supervisor Mr. Anwarul Kabir, Faculty, AIUB. His excellent supervision, constant support makes this research possible.

\section{REFERENCES}

[1] Jessica Lee Pugh. A Qualitative Study of the Facebook Social Network: the desire to influence, associate, and construct a representative and ideal identity.

[2] Richard Goettke, Joseph Christiana. Privacy and online social networking websites, May 142007.

[3] Gross, Ralph and Acquisti, Alessandro. Information revelation and privacy in online social networks. In Proceedings of the 2005 ACM workshop on Privacy in the electronic society, pages 71-80. ACM, 2005.

[4] Harvey Jones, Jose Hiram Soltren. Facebook: Threats to privacy. Massachusetts Institute of Technology, December 14 2005.

[5] Young, Alyson L and Quan-Haase, Anabel. Information revelation and internet privacy concerns on social network sites: a case study of facebook. In Proceedings of the fourth international conference on Communities and technologies, pages 265-274. ACM, 2009. 
[6] Mazman, S Guzin and Usluel, Yasemin Koçak. Gender Differences in Using Social Networks. Turkish Online Journal of Educational Technology-TOJET, 10(2):133-139, 2011.

[7] Rahaman, Arafatur and Ullah, GM. Exploration Of Influencing Factors That Effecting Facebook Privacy Awareness On Bangladeshi Undergraduate University Students. International Journal of Scientific \& Technology Research, 2013.

[8] M. Sweney. Elevator Pitch: Why Badoo wants to be the next word in social networking.

[9] Von Gregor Kucera. Wundersame Welt der Netzwerke, August 92012.

[10] Markoff, John. What the Dormouse Said: How the Sixties Counterculture Shaped the Personal ComputerIndustry. Penguin, 2005.

[11] Sarah Phillips. A brief history of Facebook, July 252007.

[12] Arrington, Michael. Eighty-five percent of college students use Facebook, 2005.

[13] Amin, Md Ruhul and Sheikh, Md Rashidul Islam. Trafficking Women and Children in Bangladesh: A Silent Tsunami of Bangladesh. Journal of Economics and Sustainable Development, 2(4):202-211, 2011.

[14] Hoque, NM Sajjadul. Female child trafficking from Bangladesh: A new form of slavery. Canadian Social Science, 6(1):45-58, 2010.

[15] A survey on social networks from female perspective in bangladesh, September 2016. https://docs.google.com/forms/d/1csZ9HoSSmjkUIA5K27sphdas1rEPcl0rDZfslPXfXk/viewanalytics.

[16] Sushmita S. Preetha. Digital Sexual Harassment in Digital Bangladesh, May 16 2015. http://www.thedailystar.net/infocus/digital-sexual-harassment-digital-bangladesh-82480.

[17] Women harassed online in Bangladesh, June 032012. https://www.takebackthetech.net/mapit/reports/view/345.

[18] 'Amended ICT law to take country towards medieval age', September 072013. http://www.thedailystar.net/beta2/news/violation-of-right-todigital-privacy/.

[19] Bangladesh National Parliament, October 082006. http://www.prp.org.bd/downloads/ICTAct2006English.pdf.

[20] 73\% women face cyber crimes: Tarana, March 082017. http://www.thedailystar.net/country/73-women-face-cybercrimes-tarana-1372849.

[21] Ahmed, SM and Hossain, Md and Haque, Md and others. Usage of Facebook: Bangladesh Perspective. Mahbubul, Usage of Facebook: Bangladesh Perspective (May 15, 2012), 2012. 